\title{
Issues in the Planning of Strategic Information Systems: An Exploratory Study
}

\author{
R. Srinivasan', E.T.V. Ravi ${ }^{2}$ \\ ${ }^{1}$ Department of Management Studies, Indian Institute of Science, Bangalore 560012 \\ ${ }^{2}$ Research Student, Department of Management Studies, Indian Institute of Science, Bangalore 560012
}

\begin{abstract}
Strategic Information Systems (SIS) are systems that are developed in response to the corporate initiative in shaping the competitive strategy of the business. They directly influence market share, earnings, and profitability; and may bring in new products, new markets, and new ways of doing business. As corporate India's spending on information systems for strategic intent climbs, Chief Executive Officers and Chief Information Officers are beginning to be confronted with the crucial question that surround all major investments. Is the planning of Strategic Information Systems proper? Are the right issues being considered while planning for SIS? The present study has been an attempt to understand the dimensions of SIS planning issues and to identify the trends in the importance given to the various dimensions in planning of SIS by the Indian Industry. A conceptual framework for understanding the dimensions of SIS planning issues was conceived. Seven measures have been identified and a construct was developed. The measures are as; (1) Business planning issues, (2) Information System planning issues, (3) Organization's System capability, (4) Organization's System Usage capability, (5) Competitors System capability, (6) Customers System capability, and (7) Suppliers System capability. The first four measures are internal to the organization, and the other three are external issues. A survey was conducted involving various types of organizations operating in India. Based on the results of the study and field experiences, some important inferences can be made. Organizations tend to give more importance to the internal issues than the issues external to the organization. In fact, the external forces are neglected. This could be due to the fact that the use of Information System for strategic purposes is still in a nascent stage in India. Organizations are
\end{abstract}

looking for internal efficiency through the use of SIS. Business Planning and Organization's System Usage capability are considered most important. With large scale restructuring and reengineering programs going on, and the adoption of the latest techniques in management; it is imperative that Business Planning issues pose a major challenge to the top management of an organization. It is felt that the presence of a good SIS in itself does not lead to competitive advantage and the proper use of the SIS in operation becomes more important. Service sector organizations give more importance to IS planning, Competitors System capability, and Customers System capability; than manufacturing sector organizations. Service sector organizations tend to be driven by the type of systems the competitors use. Service sector organizations tend to give more importance to the customer side of the organization rather than the suppliers' side; vice versa applies to manufacturing organizations. Invariably, on all measures, MNC's give more importance than the Indian companies. This feature can be attributed to the trend that MNC's are more effective and prudent in their planning approach, and many of the MNC's used in the study are innovators in the adoption of SIS in their respective areas of business.

From the viewpoint of business and IS strategies, the results are helpful to organizations, IT consultants, and IT vendors; in identifying the present trend. The lack of external orientation is found, and the need for the same to sustain/gain competitive advantage is suggested. A longitudinal study over the SIS adoption stages would help to monitor the change in trends of SIS planning of various types of organizations operating in developing economy. 